Cahiers de recherches médiévales

\title{
Les moyens de la protection privée
}

\section{Edina Bozoky}

\section{OpenEdition}

Journals

Édition électronique

URL : https://journals.openedition.org/crm/397

DOI : $10.4000 / \mathrm{crm} .397$

ISSN : 1955-2424

Éditeur

Honoré Champion

\section{Édition imprimée}

Date de publication : 15 janvier 2001

Pagination : 175-192-xiv

ISSN : 1272-9752

\section{Référence électronique}

Edina Bozoky, «Les moyens de la protection privée », Cahiers de recherches médiévales [En ligne], 8 |

2001, mis en ligne le 13 mars 2008, consulté le 15 décembre 2022. URL : http://

journals.openedition.org/crm/397 ; DOI : https://doi.org/10.4000/crm.397

Ce document a été généré automatiquement le 15 décembre 2022.

Tous droits réservés 


\title{
Les moyens de la protection privée
}

\author{
Edina Bozoky
}

1 Un foisonnement d'usages, de coutumes, de formules et d'objets attestent que dans la pratique de la religion de tous les jours, qu'on appelle aussi « domestique ", l'homme médiéval se souciait avant tout de se préserver des dangers et des maladies qui menaçaient sa propre personne, sa famille et ses biens. Pour la protection et la guérison, aux XIII ${ }^{\mathrm{e}}-\mathrm{XV}^{\mathrm{e}}$ siècles, on s'entourait d'une multitude de moyens ayant une connotation spirituelle. Censée établir une frontière invisible pour empêcher les forces démoniaques et les êtres qui leur étaient assimilées (bêtes nuisibles, mais aussi sorcières) de nuire, ou bien les chasser d'un corps, d'un lieu, ou encore pour restaurer les dégâts causés par le mal, la protection spirituelle sollicitait l'intervention des puissances célestes, pour exercer une contrainte de nature spirituelle. Dans la mentalité des utilisateurs médiévaux, ces moyens ne furent pas considérés magiques, mais constituaient soit un complément soit une alternative des recettes chimiques et des procédés physiques, matériels ${ }^{1}$.

2 Lorsqu'on procède au recensement des moyens employés, on constate qu'ils prenaient les formes les plus variées allant des pratiques ancestrales d'allure païenne à des procédés proches de la liturgie de l'Église. Dans cet essai, nous voulons présenter les pratiques utilisées dans le monde des laïcs, aussi bien dans les classes populaires que chez les bourgeois aisés ou chez les aristocrates. Les exorcismes et les bénédictions liturgiques ${ }^{2}$, ainsi que l'usage des sacramentaux par les ecclésiastiques ne relèvent pas de notre propos, bien que leur influence soit déterminante pour les pratiques du milieu laïc; nous brosserons ici une esquisse de l'ethnographie des usages prophylactiques et apotropaïques dans la vie quotidienne des hommes et femmes médiévaux.

\section{Bénédictions, charmes, brefs}

3 Les formules verbales, orales ou écrites, constituaient les moyens spirituels les plus répandus de la protection ${ }^{3}$. Dans une catégorie des prières, on demandait avec insistance l'intervention de la Vierge ou d'un saint à des fins prophylactiques, comme 
par exemple une invocation adressée à saint Roch, insérée dans un Livre d'heures (1522) :

O saint Roch, vray preservateur de feu, bossë, epydimie, je te requiers de tres bon cueur que tu me preserve et ma lignie. Mon bestial et ma mesnie mect tout en ta protection, en priant Jhesus et Marie que de peste franc nous soyons. Amen ${ }^{4}$.

\section{1. Oraison de sainte Apolline}

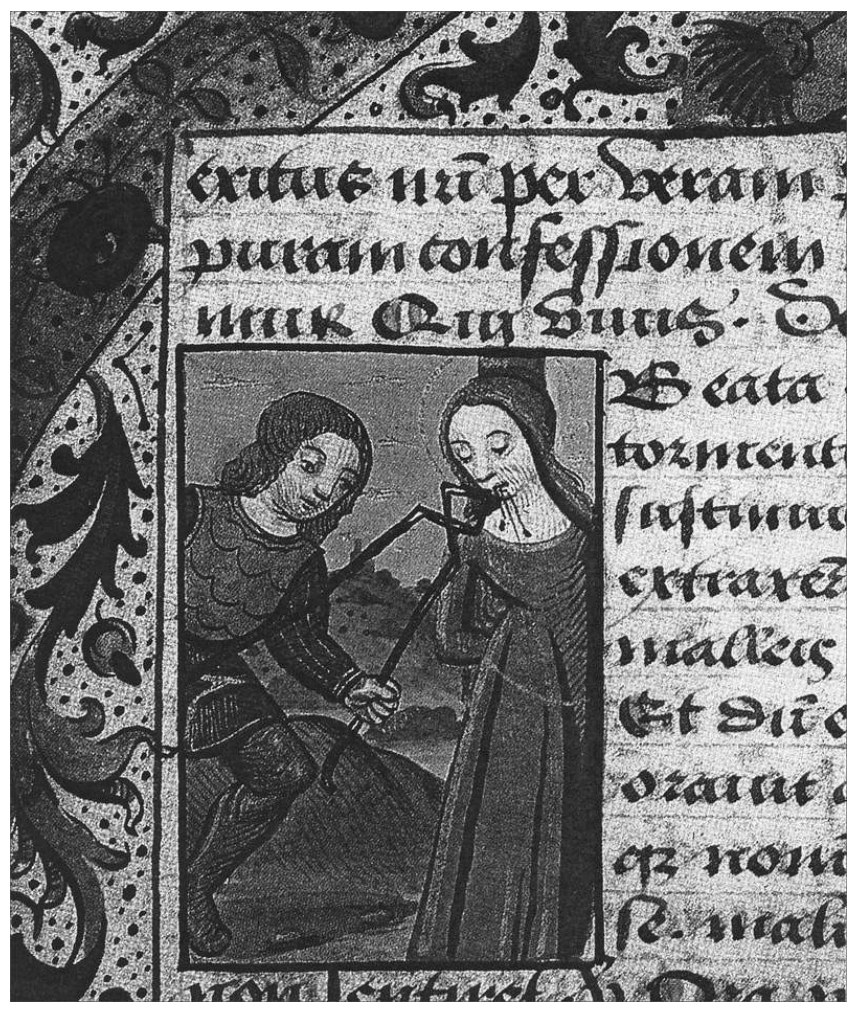

Livre d'Heures, fin XVe siècle, Poitiers, Médiathèque, ms 1097, f. 68.

4 Les prières attribuées aux saints avaient une valeur supérieure : les oraisons de sainte Apolline (ill. 1) et de saint Nicaise contre le mal de dents, la prière de sainte Marguerite, ou celle dite de Charlemagne (appelée aussi Lettre du pape Léon à Charlemagne) ${ }^{5}$; de même, les prières trouvées sur des lieux saints, comme par exemple celle inscrite sur une pierre à Saint-Pierre de Rome, celle trouvée sur le sépulcre de la Vierge dans la vallée de Josephat furent utilisées - en général sous leur forme écrite - pour être protégé. Certains de ces textes assuraient une protection universelle :

«Cest oraison qui s'ensuit fut trouvée sur le sepulchre de la glorieuse vierge marie mere de nostre seigneur. Et a telle propriété et vertu que toute personne qui la dit ou faict dire une foyz le iour ou la porte sur luy il ne moura (sic) de mort soubdaine : en eaue : en feu : ne en bataille. Item sy femme travaille mettez luy laditte oraison sur le ventre, tantoust se delivrera. Item si aucun a le hault mal tantoust sera guéry. Item qui le dira tous les iours verra la vierge marie troys foiz avant sa mort. Aussy qui la porte par bonne devotion et parfacte intention ${ }^{6}$ ». 

venait du Christ : il s'agit de la Lettre de Jésus-Christ à Abgar, roi d'Édesse, attestée depuis le IV siècle.

6 Les charmes (carmina) proprement dits, désignés ainsi dans les manuscrits médiévaux, englobaient toute une variété de formules, allant du charme narratif aux formules inintelligibles, dérivés de langues étrangères (hébreu et grec) et aux "caractères ", séries de lettres (à l'origine initiales des mots d'une phrase, ou lettres à caractère magique).

7 De même que les bénédictions et les exorcismes liturgiques, la plupart des charmes et incantations contenaient un commandement adressé aux puissances du mal, aux démons, à la maladie. Dans une catégorie particulière des formules, une partie narrative précède la conjuration proprement dite. Le récit ou seulement la brève mention d'un épisode (en général apocryphe) de l'histoire sainte introduit les paroles efficaces prononcées par le Christ, la Vierge ou un saint. L'effet de ces formules dites narratives est produit ainsi par une médiation «mythique »: " un événement qui se déroula dans le lointain passé et qui maintenant possède l'éternité et la valeur typique du mythe, est littéralement actualisé par la puissance de la formule, qui le rend présent et fécond ${ }^{7}$ ». Cette procédure, où le "médiateur" entre le mal et sa réparation (guérison) est un personnage de l'histoire sainte, renforce l'efficacité symbolique de la formule. L'une des formules des plus attestées, utilisée contre le mal de dents, mettait en scène le Christ et saint Pierre :

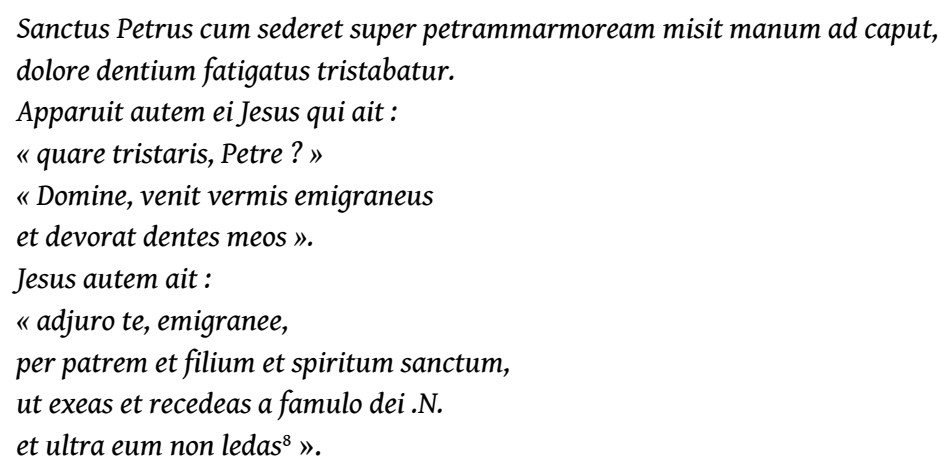

D'autres charmes contenaient des noms sacrés, énumérés fréquemment dans les brefs ${ }^{9}$, formules écrites sur des morceaux de parchemin ou autres supports (lamelle de plomb, papier) : les noms de Dieu, des anges, des sept dormants d'Éphèse, mais aussi les noms des trois Rois Mages, dont la popularité ne cessait d'augmenter à partir du XII ${ }^{\mathrm{e}}$ siècle. Dans un recueil de recettes de la fin du XIV ${ }^{e}$ siècle, pour fabriquer un bref de portée générale, on recommanda d'écrire les dix noms hébreux de Dieu sur un parchemin vierge :

Breve valde notabile et bonum dum tamen sit scriptum in pergameno virgineo, alias non valet, et nota ipsum bene et ex causis in ipso memoratis.

In nomine Ihesus Christi, vadam, revertar, morer et salutem meam faciam. Hec infra sunt nomina decem apud Hebreos, quibus nominatur Deus. Quicumque super se portaverit in igne, nec in aqua, nec in judicio, nec in bello perebit sed in omni loco remanebit imunis.

$\dagger$ Hol † Helo $†$ Joel $\uparrow$ Hic $†$ Adonay $\uparrow$ Sabahot $\uparrow$ Tetanugiacon sive Migraton † Hely † Thoma. Hec nomina porta tecum et non timebis inimicum nec venenum nec juidicium nec maleficium nec mortem nec demones nec pestem nec aliquod maleficium. Et si mulier pregnans super se portaverit, non moriretur de partu sed statim pariet ${ }^{10}$. 

du mal caduc (épilepsie), mais pouvaient avoir un emploi différent, comme par exemple arrêter le saignement : « P(er) restanquar sanc. Per restanquar sanc de (una) p(er)sona, escrieu el fron, del sanc d'aquel q(ue) sannara: Gasfar, Baltassar et Melsion, estanquara $\mathrm{se}^{11} »$.

Les mots inintelligibles et les séries de lettres (caracteres) apparurent dans les inscriptions dès le haut Moyen Âge ; en raison de leur sens secret, on leur attribuait une valeur spéciale. L'Église les condamnait sans équivoque ${ }^{12}$; cependant ils restaient très populaires et on les inscrivait souvent même sur des parures prophylactiques (cf. plus loin).

11 À partir du XIII siècle, la diffusion par écrit des formules connut un essor considérable; de même, on observe la fréquente occurrence des textes en langue vernaculaire. Véhiculées probablement autant oralement que par écrit, les formules passaient d'une langue à l'autre, produisant de multiples variantes. Si, pour la postérité, ce sont surtout les recueils de recettes médicales qui nous ont transmis les textes, à l'époque médiévale, on les utilisait avant tout sous la forme de brefs, que l'on portait sur soi occasionnellement ou en permanence. Par exemple, contre la douleur des dents, on préconisait le port d'une formule simple correspondant à un symbole de la foi : «Per la dolor de las dens. Porta en escrit sobre tu e ajas en memoria : "Benesta sia la mora que Dieus fonc nat e bategat e mort e ressusetat" ${ }^{\prime 13}$ ".

12 Certaines de ces amulettes écrites étaient très élaborées, comme la pièce de parchemin de grande taille ( 590 x $560 \mathrm{~mm}$; milieu du XVe siècle), conservée au Musée des Arts et Traditions populaires (ill. 2) ${ }^{14}$ : elle contient toute une série de formules ainsi que la Vie de sainte Marguerite, employée pour faciliter les accouchements. Les amulettes permanentes, ayant un caractère polyvalent, accumulaient les formules d'une certaine diversité. En revanche, pour venir à bout d'une maladie ponctuelle (fièvre, mal de dents, saignement), on se servait d'une formule unique : parfois même le malade devait la consommer, avec le support matériel sur lequel on l'inscrivait (pomme, hostie). 
III. 2. Parchemin-amulette contenant la Vie de sainte Marguerite (XIVe siècle)

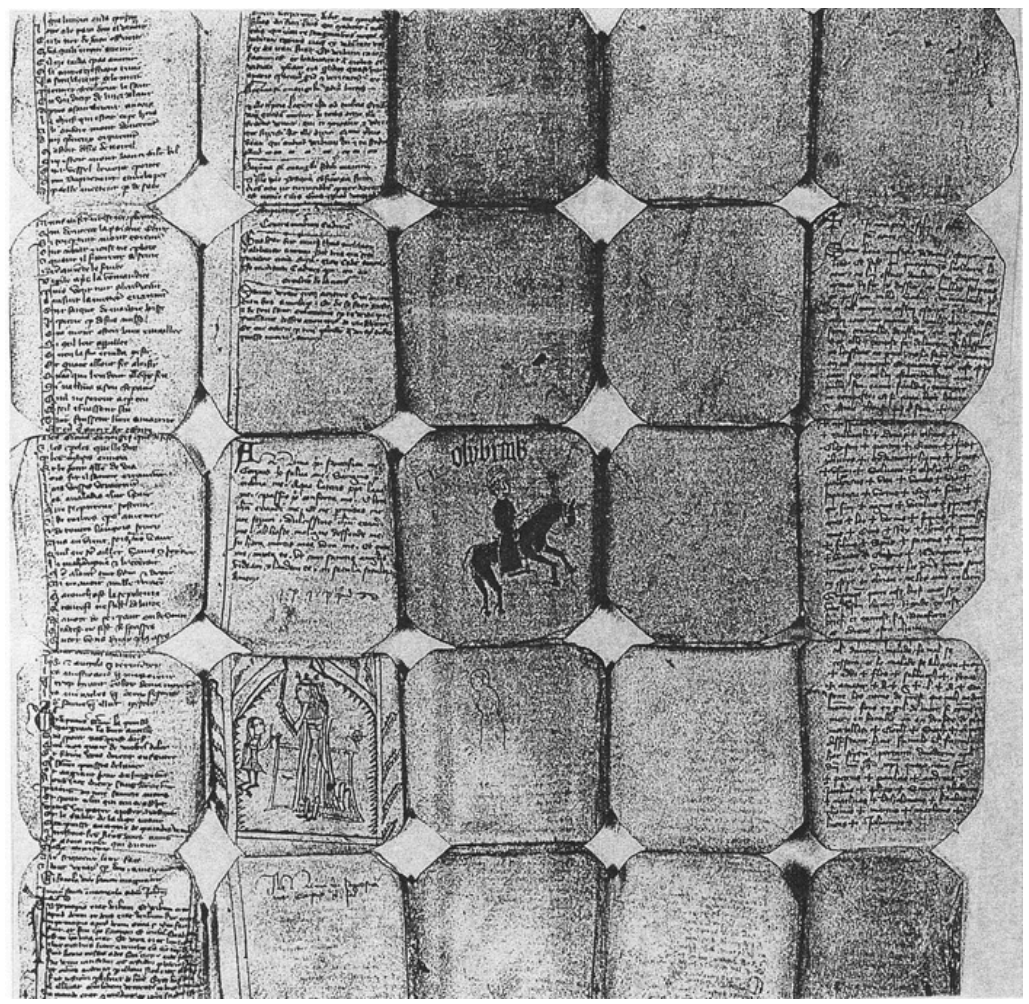

Paris, Musée des Arts et Traditions Populaires.

13 On peut imaginer que tout un chacun pouvait utiliser, à un moment ou autre de sa vie, les formules de protection et de guérison. Le Marteau des sorcières mentionne en particulier que les commerçants et les marchands ${ }^{15}$ ou les soldats ${ }^{16}$ portent avec eux des bénédictions et des charmes. En 1472, un enlumineur nommé Jean Guillemer fut arrêté en raison d'un complot; on trouva sur lui une quantité de brefs en parchemin et en papier, qu'il avait rassemblés lors de ses déplacements ${ }^{17}$.

\section{Des gemmes aux reliques: les joyaux prophylactiques}

Si tout le monde pouvait obtenir assez facilement des brefs sur parchemin ou papier, les pierres précieuses, les bijoux-reliquaires furent réservés aux riches nobles ou bourgeois; les gens du peuple se contentaient d'amulettes d'origine végétale ou animale plus simples, qui n'ont pas pu être conservées jusqu'à nos jours.

Pour la confection des joyaux ornés de pierres précieuses, on prenait vraisemblablement en considération les renseignements contenus dans les Lapidaires qui transmettaient les croyances en la vertu protectrice des pierres. Les Lapidaires médiévaux, rédigés d'abord en latin, puis à partir du XII siècle, en versions vernaculaires, puisaient leur matière de base chez Marbode, tout en l'amplifiant et l'enrichissant de nouveaux apports. Par exemple, dans la première version anglonormande du Lapidaire de Marbode, l'émeraude donne la richesse et fait bien parler ceux qui la portent; elle guérit également de la fièvre, protège contre la goutte, est bénéfique pour les yeux ${ }^{18}$. L'agate guérit des enflures, l'enfonture (mal causé par l'excès 
de la nourriture); lavée avec du vin, elle guérit les dents, fait revenir les règles à la femme qui se baigne dans l'eau où la pierre fut lavée; jetée au feu, elle chasse les serpents et les diables, détruit la malignité des charmes, des mauvais sorts et des poisons. La femme enceinte qui boit de l'eau dans laquelle l'agate a baigné durant trois jours, accouchera sans difficulté ${ }^{19}$. Les Lapidaires de gemmes intaillées donnaient la clé de l'utilisation apotropaïque des pierres gravées. Très appréciées au Moyen Âge, elles connurent une véritable vogue surtout après le pillage de Constantinople en 1204, avec l'importation massive de camées et d'intailles en Occident ; mais la plupart des pierres tenues pour antiques sont en fait des imitations médiévales ${ }^{20}$. Les images des pierres étaient censées garantir la santé, le courage, la richesse. Par exemple, une pierre où était représenté Persée brandissant son épée et tenant la tête de Gorgon, protègeait son porteur de la tempête, de la foudre, de la haine (envie) et du diable ${ }^{21}$. Selon l'Inventaire de son mobilier, le roi Charles V possédait une pierre « qui guérit la goutte en laquelle est entaillé ung roiy ${ }^{22}$ ».

Parmi ces " pierres », certaines sont en fait des matières d'origine végétale ou animale, mais les Lapidaires leur attribuaient des origines mi-fantaisistes, mi-scientifiques. Le corail, décrit comme un arbre poussé en mer, pétrifié et devenu rouge au contact de l'air, protégeait celui qui le portait, selon les Lapidaires, contre la foudre et la tempête, de même que les champs où il se trouvait; il rendait d'ailleurs abondante la récolte et chassait les fantômes. Monté en bijou, serti d'or, il apparaît fréquemment sur les tableaux de la fin du Moyen Âge représentant l'Enfant Jésus (ill. 3). L'usage de l'ambre et de l'ébène pour des bijoux-amulettes venait de l'époque antique. Les Lapidaires classaient l'ambre (en latin allectorium) parmi les pierres; elle rendait invincible, aimable et séduisant. À propos de l'ébène, Jean Corbechon, traduisant Barthélemy l'Anglais, indiqua qu' " on souloit metre ce fust pres des enfans nouveaulx nez afin qu'ilz ne eussent paour des noires choses, sicomme dit Plinius ». Les dents de loup ou de chien, suspendues au cou des enfants, les protégeaient contre le mal de dents, mais aussi contre le mal lunatique ${ }^{23}$. 


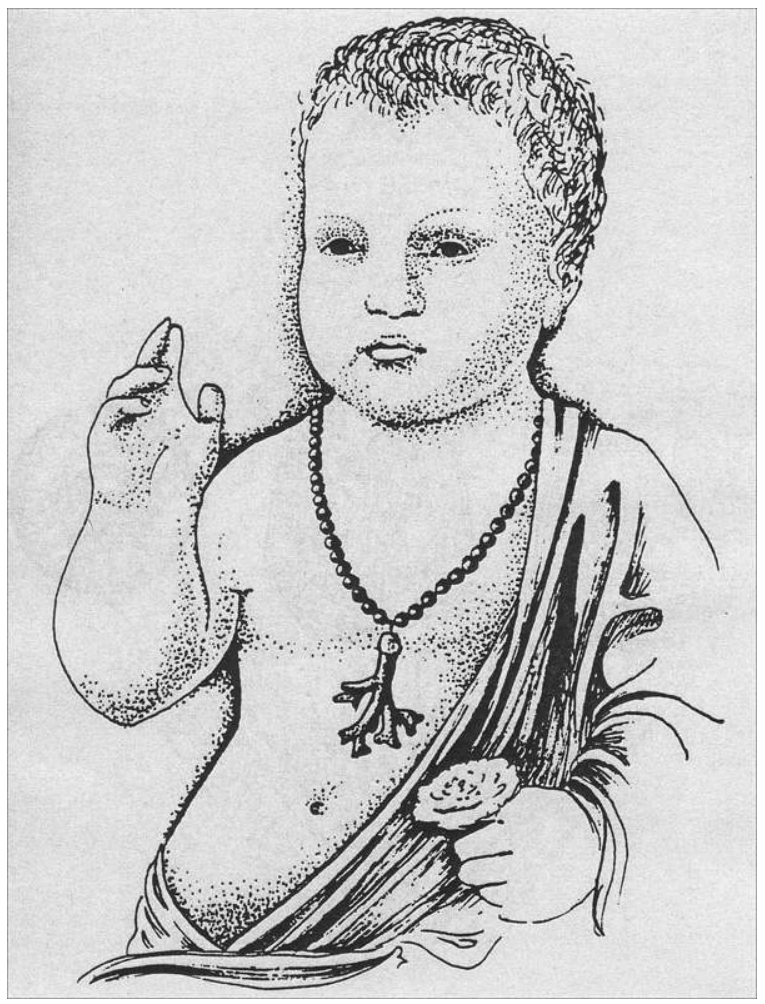

Urbino, Galerie Nouvelle des Marches (dessin de B. Parent).

D'une façon générale, les joyaux et les parures de vêtement pouvaient avoir une fonction prophylactique, au-delà de leur valeur esthétique et monétaire. Quelques pièces précieuses, retrouvées parfois au hasard dans un fleuve ou dans le sol, témoignent de l'usage de graver des formules apotropaïques sur les bagues et sur les broches. On connnaît quelques broches circulaires gravées sur le revers d'inscriptions du nom de Jésus, ou de ceux des Rois Mages (broche de Glenlyon, $\mathrm{XV}^{\mathrm{e}}$ siècle, British Museum) ${ }^{24}$. Une bague du XIII ${ }^{\mathrm{e}}$ siècle (Angleterre) ${ }^{25}$, contenant une dent de loup, porte l'inscription suivante: † Buro †Berto †Berneto †Consumatum e(st). Sont connues également quelques bagues gravées du verset Iesus autem transiens per medium illorum ibat (Luc IV, 30). Selon Jean de Mandeville, " certains, quand ils redoutent les larrons ou les ennemis sur la route, disent : "Mais Jésus, passant au milieu d'eux, s'en alla". Ainsi, en souvenir de ce que Jésus passa parmi les Juifs cruels et leur échappa, on demande d'échapper en toute sécurité au péril des larrons ${ }^{26} »$. Une bague originaire d'Italie (XIV ${ }^{\mathrm{e}}$ siècle), est ornée d'une crapaudine, réputée de protéger contre les maladies rénales ; outre le verset de Luc, y figure un verset de l'Évangile de Jean (I, 14) : Et verbum caro factum est.La plus célèbre des bagues-amulettes est une magnifique pièce en or, trouvée à Coventry, porte à l'extérieur la représentation du Christ sortant du tombeau avec les instruments de sa Passion ainsi que les symboles de ses cinq plaies, identifiées comme les Fontaines de Pitié, de Miséricorde, de Réconfort, de Grâce et de Vie Éternelle. À l'intérieur, on a gravé une formule apotropaïque composite, dont la première partie contient le début de l'Oraison des Cinq plaies ; suivent les noms des rois mages ainsi que les mots "magiques» ananyzapta (charme contre l'épilepsie) tetragrammaton (le nom hébreu de Dieu en quatre lettres). L'inscription des noms des rois mages sur les bagues devait être fréquente, tout comme celle des mots empruntés à 
une langue étrangère. Par exemple, sur une bague du XIV siècle, on peut lire : † AGLA $\uparrow$ ADOS † VDROS † IDROS † TEBAL † GVT † G (dont AGLA est composé des initiales de mots hébreux Ate Gebir Leilam Adonai, signifiant « Tu es majesteux éternellement, Seigneur »; le reste de la formule, contenant des mots grecs et leur déformations, est couramment associé aux charmes contre le mal de dents). Dans d'autres cas, la puissance de ces mots étranges fut renforcée par la représentation de Dieu, de la Vierge et des saints ${ }^{27}$. Les bagues dites "iconographiques", avec l'image gravée des saints sont considérées comme spécifiques à l'Angleterre, où elles sont attestées dès le XIV ${ }^{\mathrm{e}}$ siècle $^{28}$.

Également en Angleterre, à partir du règne d'Édouard II, un cérémonial royal effectué le Vendredi Saint, avait pour but de fournir des cramp-rings, des anneaux médicinaux censés soulager les crampes, les spasmes et l'épilepsie. Le roi déposait sur l'autel de la monnaie d'or et d'argent, puis le «rachetait " avec des pièces ordinaires; on fit fabriquer des anuli medicinales avec le métal précieux ainsi récupéré29.

Les enseignes de pèlerinage, petites plaquettes de plomb et d'étain que les pèlerins rapportaient de leur visite à un sanctuaire, possédaient également une valeur apotropaïque $^{30}$. On les fixait sur les vêtements, ou l'on les cousait dans les livres d'heures, notamment les « véroniques ", images de la Sainte Face de Rome, reproduites le plus souvent sur cuir ou sur parchemin (ill. 4) ${ }^{31}$.

\section{4. Ampoule et enseigne de pèlerinage}
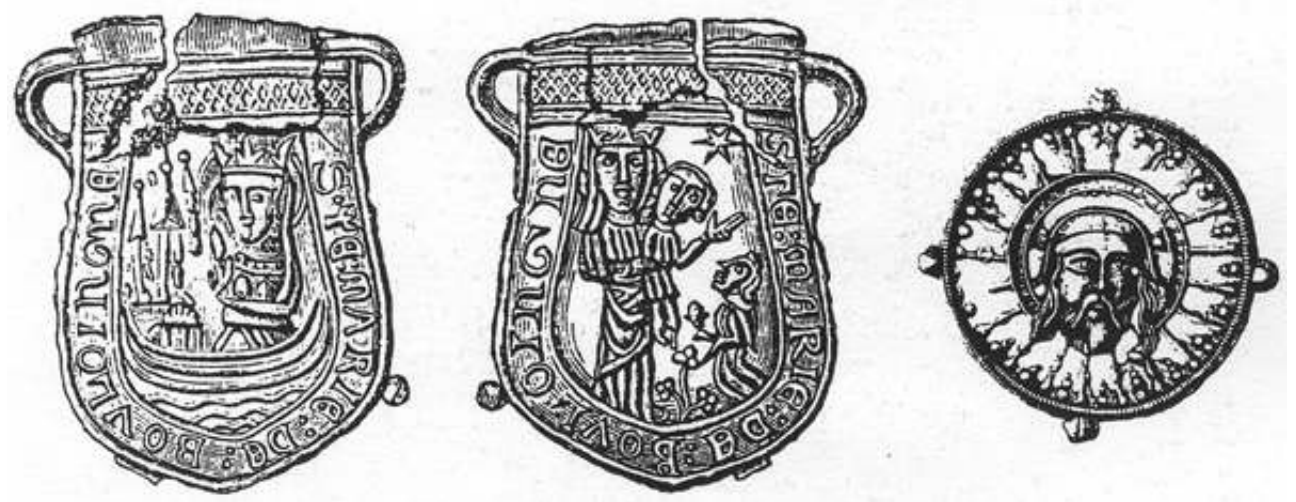

Ampoule : Notre-Dame de Boulogne ( $2^{\mathrm{e}}$ moitié du XVe siècle) ; enseigne : Rome, sainte Face (fin XV_début XVIe siècle) (gravures).

Les pendentifs portés au cou pouvaient être des croix ou des médailles simples, mais parfois il s'agissait de véritables chefs-d'œuvre complexes, réunissant les vertus des inscriptions, des images et des objets bénis. Récemment une monographie a été consacrée à un pendentif du XV $\mathrm{XV}^{\mathrm{e}}$ siècle en or, en forme losangée, trouvée en 1985 près du château de Middleham (ill. 5) ${ }^{32}$. L'avers du joyau, un petit boîtier, est décoré d'un saphir et gravé de l'image de la Trinité. Le cadre porte une inscription mi-chrétienne, mi-magique : Ecce agnus dei qui tollit peccata mundi - Tetragrammaton-Ananizapta. Sur le revers, la Nativité et sur la bordure, quinze saints auxiliaires sont représentés. Quant au contenu du joyau, il n'en reste que de petits morceaux d'étoffes brodés d'or; selon toute vraisemblance, le boîtier renfermait un médaillon rond en cire de l'Agnus Dei, que l'on portait souvent en récipients de bronze ou de métal précieux. Par exemple, le Trésor de Quedlinburg conserve plusieurs capsules-pendentifs Agnus Dei du XV $\mathrm{XV}^{\mathrm{e}}$ siècle, dont trois en argent gravé ; un quatrième, constitué de deux plaques de verre, renferme l'Agnus Dei et l'image de saint Christophe en parchemin (ill. 6) ${ }^{33}$. 
III. 5. Pendentif de Middleham (XVe siècle)

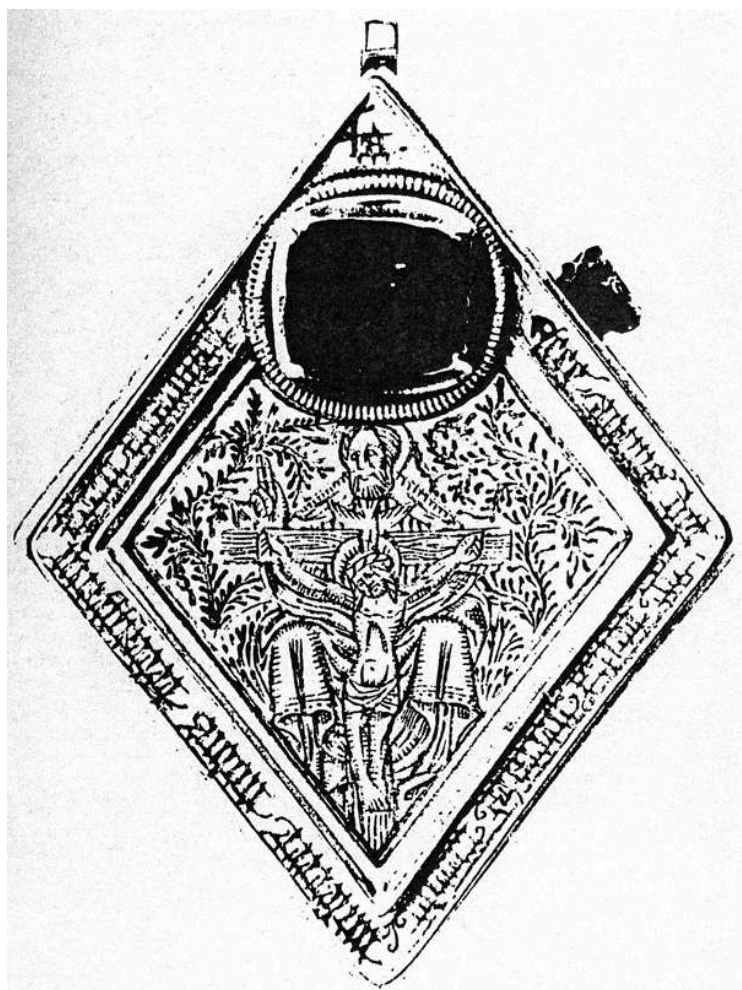

York, The Yorkshire Museum.

III. 6. Capsule pour Agnus Dei avec l'image de saint Christophe ( $2^{\mathrm{e}}$ moitié du XVe siècle)

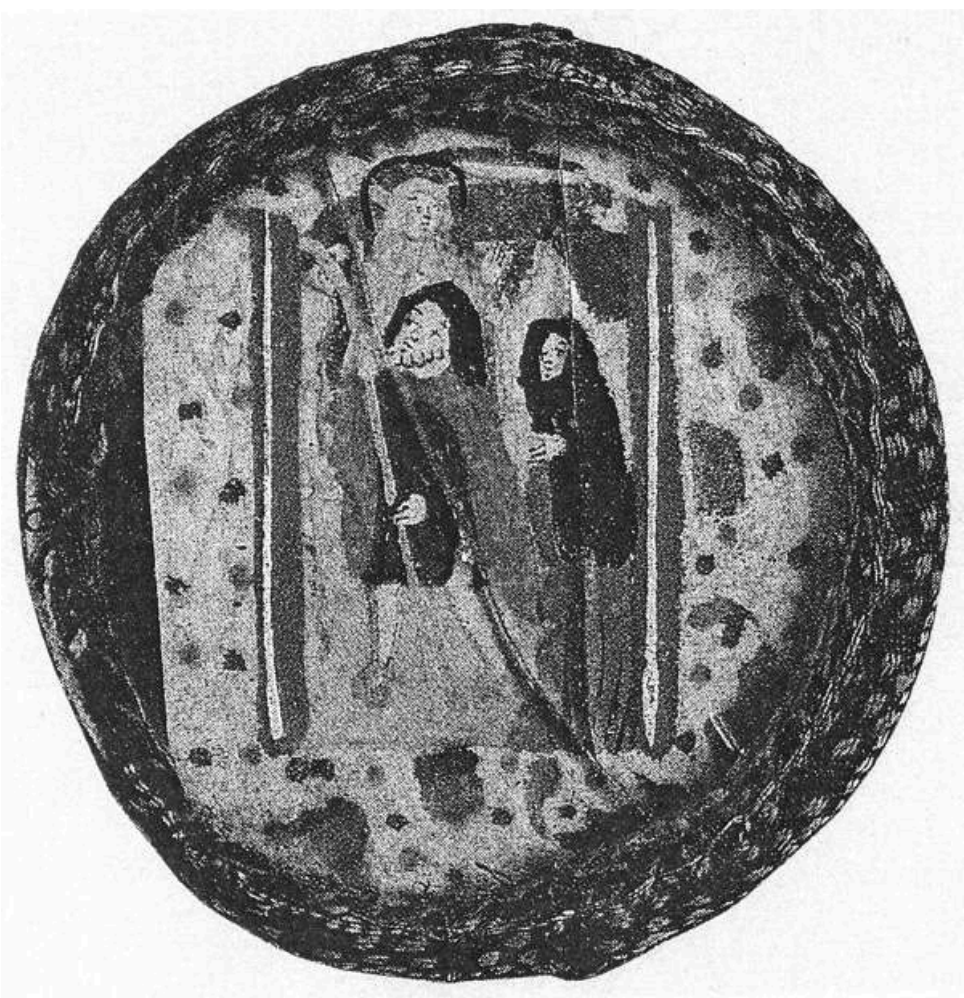

Quedlinburg, Trésor. 
21 bénédiction pontificale. Fabriqués avec un mélange de baume, de cire d'abeille pure provenant du cierge pascal, et de chrême, ils représentaient l'Agneau de Dieu et furent donnés en cadeaux à des personnages importants par les papes dès le XII ${ }^{\mathrm{e}}$ siècle. Ces objets devaient détruire le péché et augmenter la vertu, protéger la femme enceinte, protéger du feu et de l'eau. En raison de leur grande valeur, on en produisait également des faux, comme en témoignent trois moules découverts à Newport.

Parmi les objets prophylactiques, les petits reliquaires, portés en pendentifs ou attachés à l'étoffe des vêtements, furent sans aucun doute les plus précieux. Depuis le haut Moyen Âge, selon les témoignages textuels, leur vertu miraculeuse fit ses preuves ; mais la plupart des reliquaires personnels nous sont parvenus seulement des derniers siècles médiévaux. Certains sont simples, comme deux pendentifs du Trésor de Quedlinburg (autour de 1400): les fragments de reliques furent présentés sous une lentille de cristal entouré d'un cadre quadrilobé; sur le revers, les lettres du mot hilf (aide) sont inscrites aux quatre extrémités de la croix (ill. 7) ${ }^{35}$.

III. 7. Reliquaires-pendentifs (fin XIII ${ }^{\mathrm{e}}$ siècle)
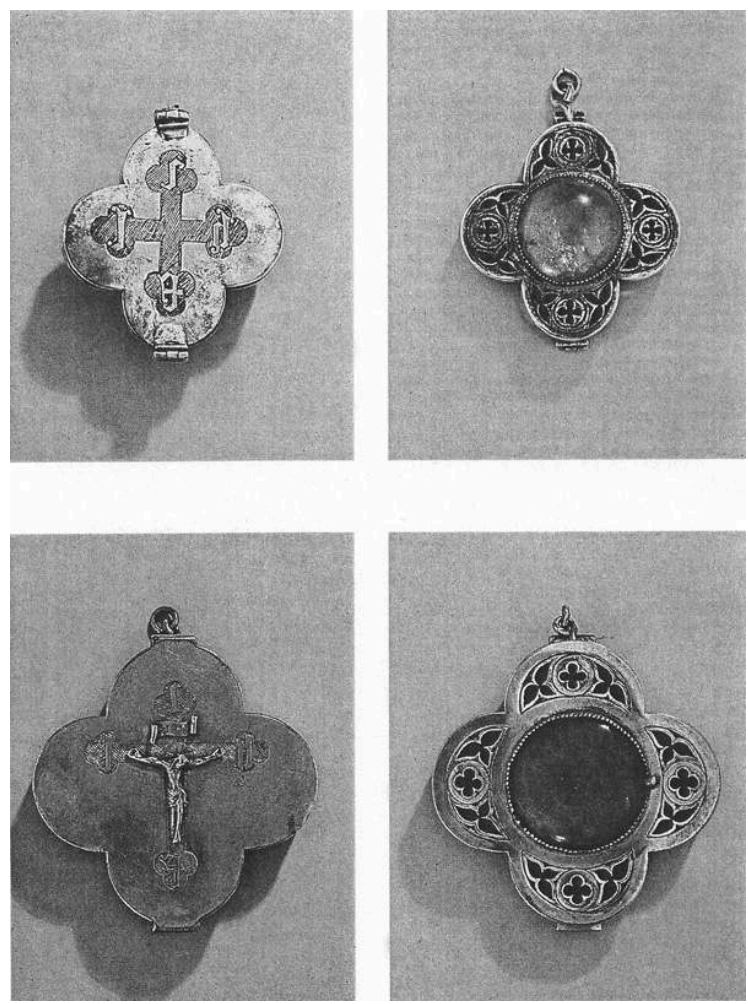

Quedlinburg, Trésor.

Mais dans les trésors royaux et princiers, les reliquaires personnels avaient souvent une forme extrêmement sophistiquée. Le bijou-reliquaire de la Sainte Épine (Paris, vers 1340), est une petite boîte de forme ovale irrégulière, recouverte d'un feuillet de parchemin, avec la scène de la Nativité, et de trois feuilles d'or émaillées, représentant la Vierge à l'Enfant trônant, la Présentation au temple et la Fuite en Égypte ainsi que la Descente de croix et la Crucifixion (ill. 8) ${ }^{36}$. D'autres reliquaires pendentifs avaient la forme d'un petit tableau, comme la plaque émaillée avec l'image de sainte Catherine, 
dont le revers, recouvert d'une plaque de cristal, contenait la relique (Paris, vers 1380 : ill. 9) $)^{37}$.

III. 8. Bijou-reliquaire de la Sainte Épine (vers 1340)

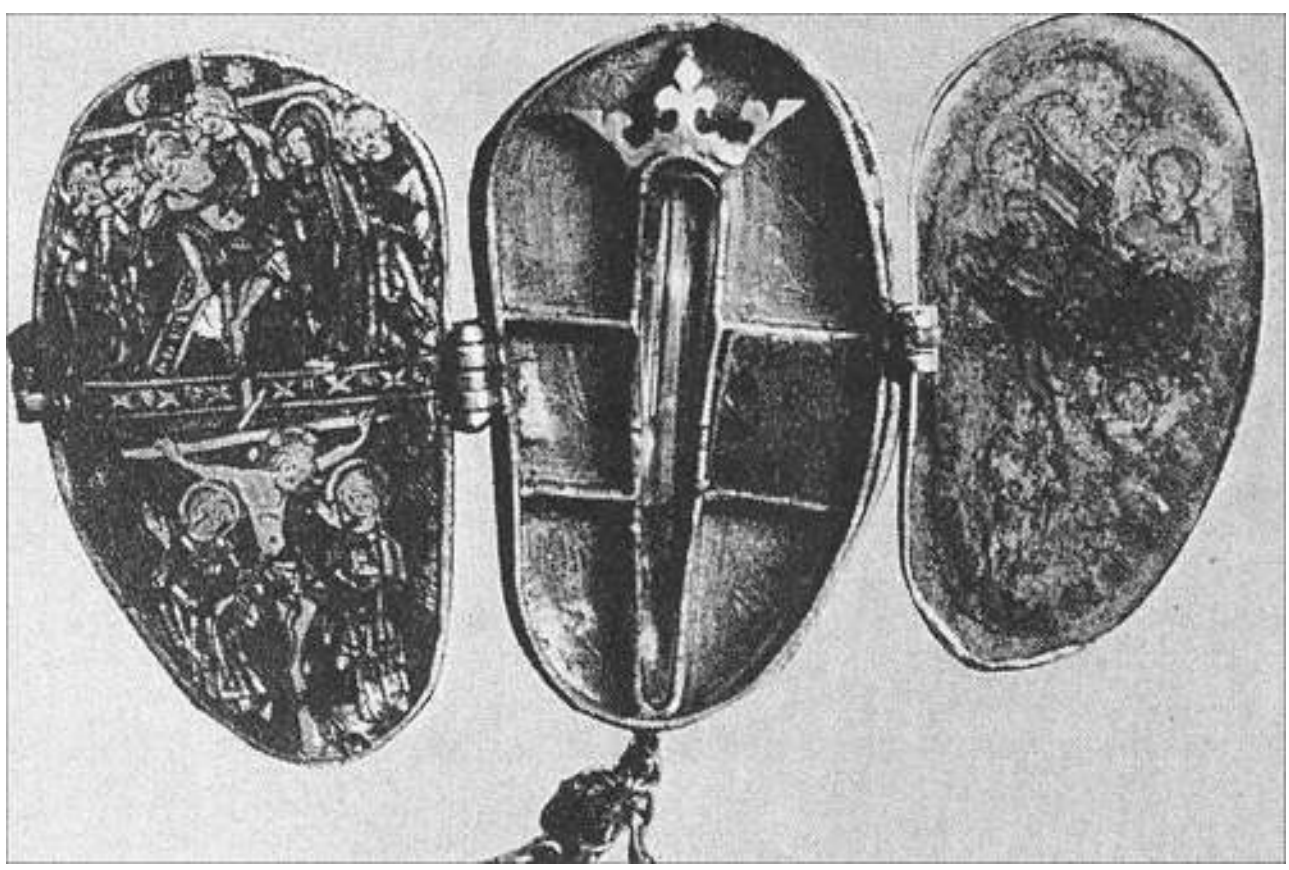

Londres, British Museum.

III. 9. Tableau-reliquaire ave l'image de sainte Catherine (vers 1380)

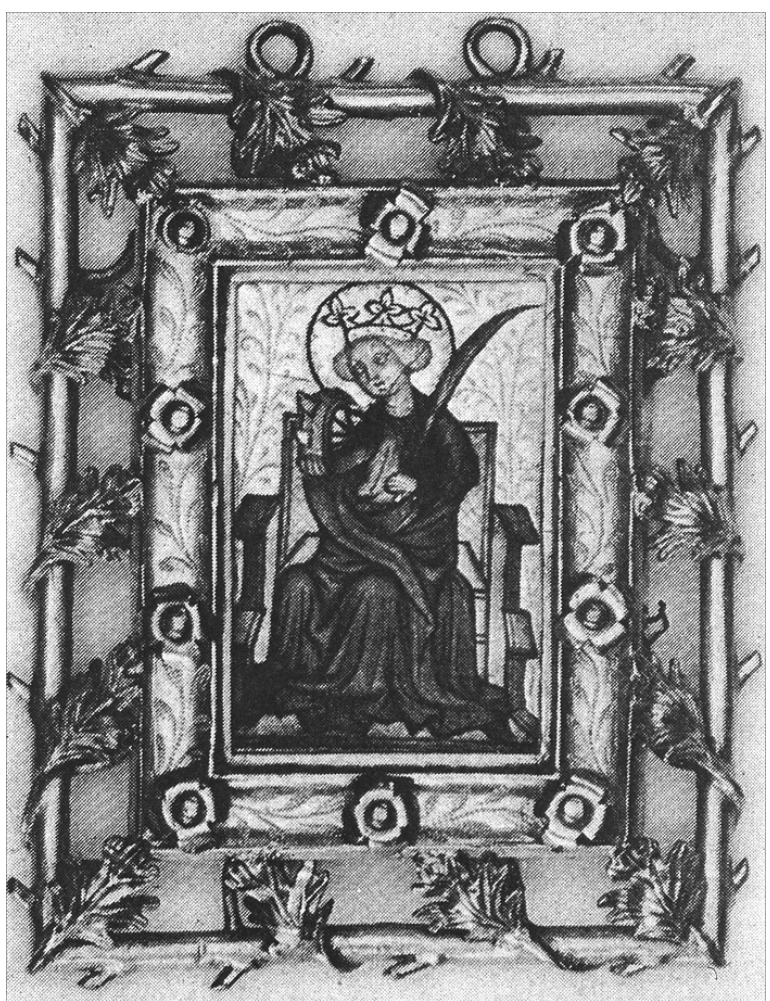

Londres, Victoria and Albert Museum. 
Des médaillons-reliquaires abritaient, de la même façon, les parcelles de reliques au revers. Une très belle pièce est conservée au Musée du Moyen Âge de Paris. C'est un médaillon (Paris, vers 1370-80) qui renfermait selon les inscriptions plusieurs reliques christiques; son avers montre du Christ à la Colonne, entouré de deux donateurs à genoux (ill. 10) ${ }^{38}$. Enfin, on portait aussi des fermails-reliquaires fixés au vêtement comme des parures. Sur une pièce du Musée du Moyen Âge, où la plaque centrale porte un aigle couronné et est parsemée de pierreries, les parcelles de reliques étaient présentées dans les logettes du cadre octolobé (milieu du XIV ${ }^{\mathrm{e}}$ siècle : ill. 11) ${ }^{39}$.

III. 10. Médaillon-reliquaire (vers 1370-1380)

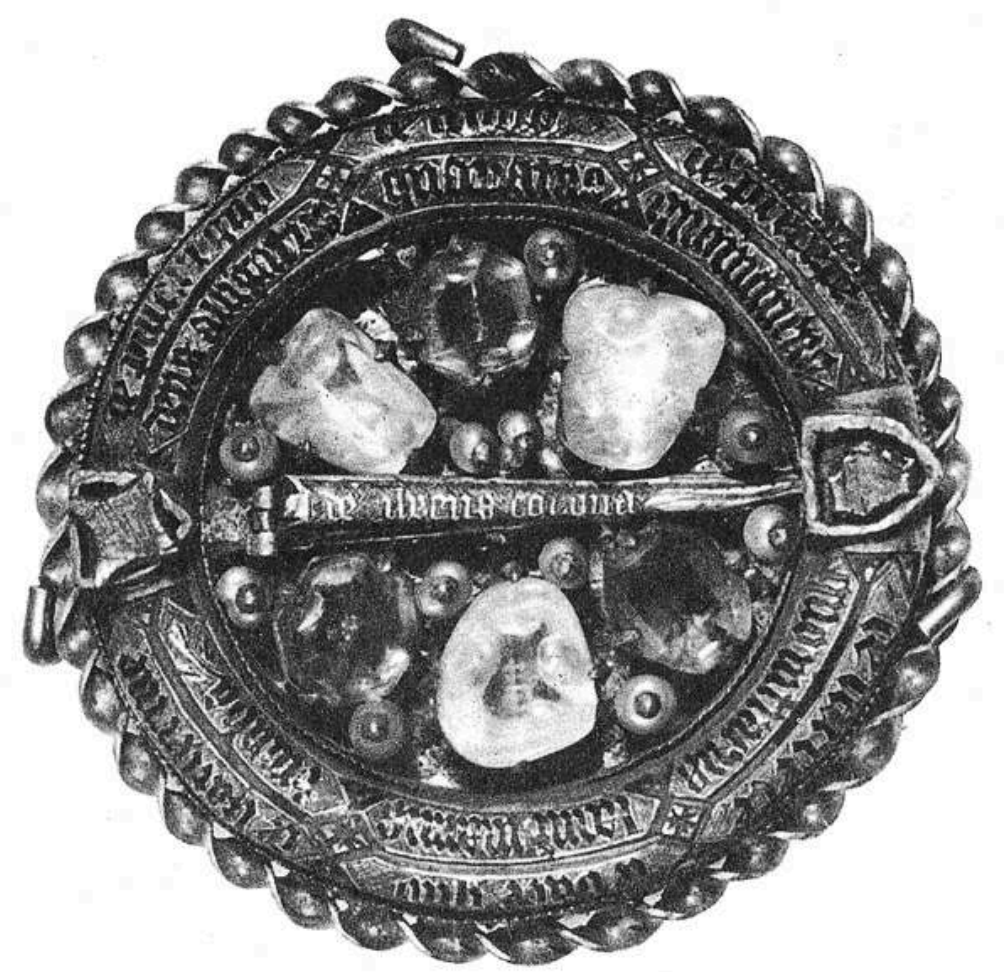

Paris, Musée du Moyen Âge. 


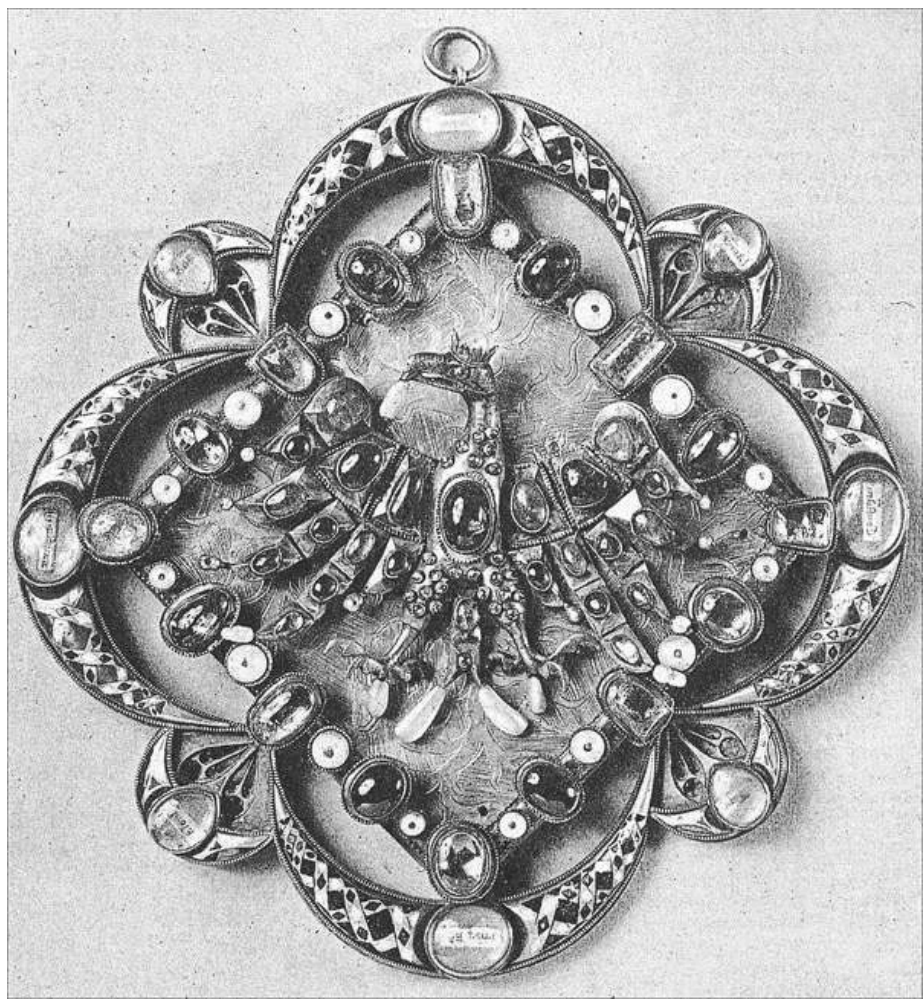

Paris, Musée du Moyen Âge.

Soulignons que les pièces conservées ne constituent qu'une partie infinitésimale des trésors royaux et princiers que nous connaissons en revanche par les Inventaires ou par les comptes. Dans l'Inventaire du mobilier de Charles $\mathrm{V}$, sont énumérées des dizaines et des dizaines de reliquaires "pendans", de camées, de bijoux et d'autres menus objets précieux, en partie liées à la protection spirituelle et à la dévotion. Quant à la circulation de ces objets, le $1^{\mathrm{er}}$ jour de l'An, on en offrait pour les étrennes avec d'autres cadeaux de valeur, comme par exemple les comptes de Philippe le Hardi en témoignent: "Le $1^{\text {er }}$ jour de l'an 1366, le duc de Bourgogne donna en bonnes étrennes » : à la reine (Jeanne de Bourbon) « un joyau d'or à mettre reliques, à pierre(s) prétieuses, du prix de 250 frans d'or »; au roi (Charles V), un autre joyau «à pierres prétieuses, à mettre reliques, du prix de $8001 .{ }^{40} \ggg$.

\section{Images et mesures}

Aux $\mathrm{XIII} \mathrm{e}^{\mathrm{X}} \mathrm{XV}^{\mathrm{e}}$ siècles, les images de dévotion et les statuettes se répandirent et entrèrent progressivement dans les foyers. À la fois supports de la piété personnelle et objets prophylactiques, les représentations sacrées prirent une valeur semblable à celle des corps saints. A. Vauchez a constaté qu' « au terme de l'évolution, l'image finit par jouer le même rôle que les reliques : on l'apposa sur la partie du corps malade ou lésée, après avoir invoqué le nom du saint ${ }^{41}$ ». Les images pieuses se diffusèrent surtout à partir du XIV ${ }^{e}$ siècle grâce à la technique de la xylographie; mais à cause de leur fragilité (papier), la plupart d'elles ont disparu. On les fixait sur le mur ou à l'intérieur des coffres et des armoires. La Bibliothèque Nationale possède une collection unique de 
treize coffrets de voyage ainsi ornés à l'intérieur d'une image prophylactique ${ }^{42}$. Certaines de ces images ont même été collées à l'intérieur des tombeaux. : "qui ne veut ne pas être blessé à la tête par un coup ou une arme, doit enlever la tête de l'image : pour protéger son cou, il doit enlever le cou ; pour le bras, il enlève ou brise le bras et ainsi de suite, parfois jusqu'à la ceinture et parfois totalement. Et c'est la raison pour laquelle sur dix statues (images) placées dans les carrefours et les champs il en reste à peine une qui soit entière. D'autres se procurent l'invulnérabilité en emportant ces membres brisés ou parfois en prononçant des mots sacrés et même inconnus ${ }^{47} »$. L'historien Rigord rapporte une anecdote miraculeuse dont la fin suggère déjà l'existence d'une telle pratique. Lors du sac du bourg de Déols, en 1187, l'un des Cotteraux, au service des Plantagenêts, brisa le bras de l'enfant Jésus de la statue qui se trouvait au-dessus du porche; la statue mutilée se mit à saigner et le sang recueilli fit des miracles; quant au bras, Jean Sans-Terre, « le plus jeune fils du roi d'Angleterre, qui avait été envoyé par son père et se trouvait là par hasard, l'emporta avec lui comme une relique avec honneur et respect ${ }^{48} »$.

31 L'essor de la dévotion à la Passion du Christ produisit également une nouveauté apotropaïque : la représentation des Arma Christi, mais avant tout celle de la plaie du côté, ainsi que la mesure exacte de la longueur du Christ, celle de la plaie du côté, ou encore celle des clous de la crucifixion, etc., connurent une utilisation à des fins de protection $^{49}$. Les textes qui accompagnent parfois les représentations des mesures indiquent que ces dernières étaient assimilées aux reliques : elles avaient été importées de Constantinople dans un écrin d'or pour Charlemagne; elles préservaient, à condition de les regarder et de porter sur soi, d'une série de dangers et de maux. Ces images se trouvaient souvent dans les Livres d'Heures, mais circulaient aussi sur des feuilles volantes ${ }^{50}$. L'enlumineur Jean Guillemer porta sur lui, entre autres brefs, un «feuillet de papier, qui est la mesure de la longueur de JHESU CRIST ». Il l'avait reçu à 
Bruxelles d'un Allemand, qui le tenait d'un Cordelier de Jérusalem; et il lui dit « que quiconques le porteroit sur lui, jamais ne lui viendroit mal'51 (ill. 12)».

\section{12. Mesure de la plaie du côté du Christ}

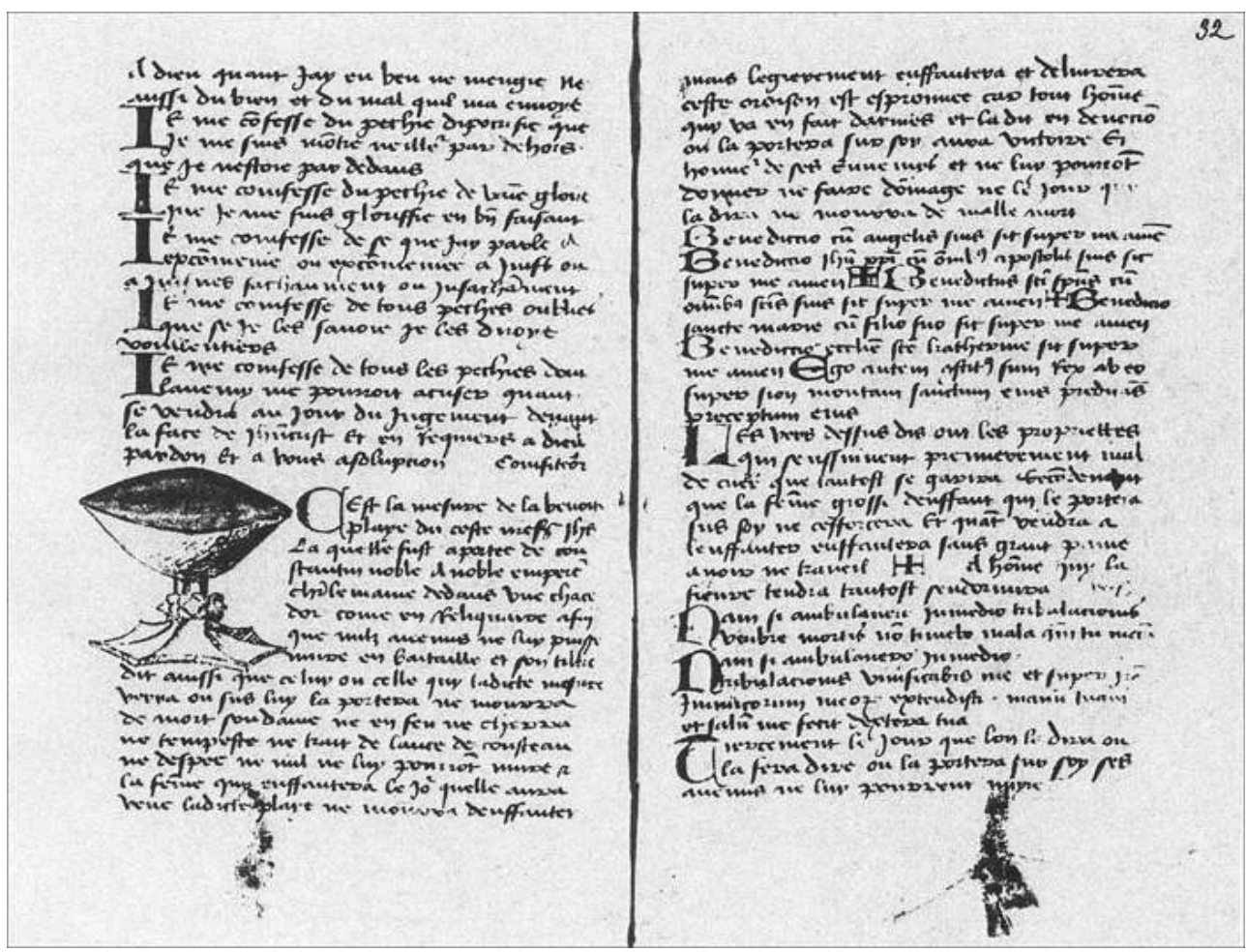

Paris, BNF, ms fr. 14017, fol. 31v-32.

\section{Pratiques rituelles}

Le mésusage des sacrements, en particulier de l'Eucharistie, provoquait immanquablement la condamnation par les autorités ecclésiastiques. En effet, l'essor du culte de l'Eucharistie eut des répercussions sur la religion " domestique » : on se mit à attribuer à l'hostie consacrée une puissance miraculeuse autre que la transmission de la grâce divine. Dès le XII ${ }^{\mathrm{e}}$ siècle circulaient des récits de miracles sur le détournement de l'hostie à des fins prophylactiques. Entre 1135-44, Pierre le Vénérable, abbé de Cluny, rapporta un miracle qui fut ensuite diffusé dans les recueils d'exempla avec quelques variantes. Dans la version de Pierre le Vénérable, un paysan auvergnat ramena l'hostie consacrée chez lui pour la déposer dans sa ruche, car « on lui avait dit, en effet, que s'il insufflait aux abeilles contenues dans la ruche le corps du Seigneur retenu dans sa bouche, aucune désormais ne mourrait, aucune ne s'enfuirait, aucune ne dépérirait, mais toutes seraient conservées intactes et lui-même en retirerait un profit beaucoup plus grand qu'auparavant ». Mais le sacrilège se dévoila par un miracle l'hostie se transforma en un nouveau-né -, et le châtiment de Dieu frappa l'endroit où l'événement eut lieu : " en peu de temps, ce lieu auparavant peuplé retourna à l'état de désert, ses habitants s'étant dispersés pour diverses raisons ${ }^{52}$ ". Le récit de l'hostie dans la ruche devint un exemplum assez populaire. Étienne de Bourbon en rapporta une version quelque peu différente : d'après sa version, on conseilla au paysan de placer dans une ruche l'hostie le jour de Pâques ; pour la vénérer, les abeilles lui construisirent 
une église en cire dans une ruche ${ }^{53}$. Quant à l'emploi de l'Eucharistie pour des buts "magiques", il fut la cible des condamnations dans les manuels des inquisiteurs et d'autres ouvrages analogues. Bernard Gui préconisait «l'enquête sur ces pratiques qui sentent une superstition quelconque, l'irrespect, l'injure vis-à-vis du culte divin et des lieux consacrés. Item, on s'enquerra de cette pratique qui consiste à conserver l'eucharistie, à dérober aux églises le chrême ou l'huile sainte ${ }^{54}$ ».

Dans les réceptaires contenant des charmes, on indiqua parfois les procédures qui devaient garantir l'efficacité des formules verbales. Ces opérations imitaient de près les rituels ecclésiastiques, avec la différence - essentielle - que l'officiant n'était pas un prêtre.

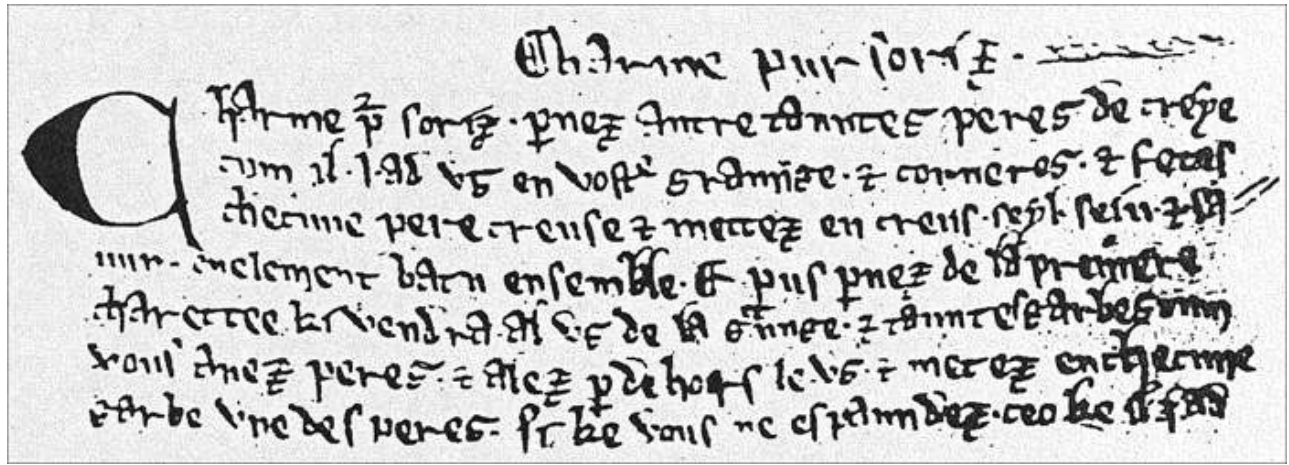

Oxford, Bodleian Library, ms Digby 86, fol. 32.

Un charme pur soriz en anglo-normand, censé protéger la grange (ou plutôt la récolte engrangée), conservé dans un manuscrit du XIII siècle (Oxford, Bodleian Library, Digby 86: ill.13), réunit des éléments matériels, liturgiques et dramatiques. Premièrement, l'officiant doit ramasser des pierres de craie qui se trouvent à la porte de la grange, les creuser et y mettre du sel, de la graisse et du savon mélangé. Ensuite il doit prendre, dans la première charrette qui arrive à la grange, autant de gerbes qu'il y a de pierres, et mettre dans chaque gerbe une pierre. Saisissant la première gerbe, il doit dire In nomine Patris et Filii et Spiritus Sancti, amen, puis l'emporter au milieu de la grange et dire un Pater Noster; il faut répéter la même chose avec les autres gerbes. Il faut aussi poser au-dessus de la porte de la grange une pierre avec l'inscription Jesus, et aux quatre angles de la grange, des pierres avec les noms des quatre évangélistes. Après cela, l'officiant doit aller à la porte de la grange et dire à son compagnon qui reste dedans : " Je vous conjure au nom du Père et du Fils et du Saint Esprit que vous me dites de quoi vivront les rats et les souris dans cette grange ». Et l'autre répondra : «Je vous dis par le Père et le Fils et le Saint Esprit qu'ils ne vivront que du sel, de craie, de la graisse et du savon ». Et ce dialogue doit être répété trois fois, et complété par la récitation du Pater Noster également trois fois ${ }^{55}$.

Des rites calendaires plus simples mais sans doute largement répandus s'attachaient aussi à la protection de l'individu et de ses biens. Remontant aux traditions ancestrales (" païennes »), les coutumes de Noël et du premier de l'An, du mois de mai, de la SaintJean, etc. garantissaient l'intégrité, la santé etc. des personnes, du foyer, des bêtes, des champs. 

poèmes la coutume selon laquelle les femmes entouraient la tête le soir de la SaintJean, d'une couronne d'armoise, en croyant qu'ainsi ni le vertige ni l'épilepsie ne pouvaient les atteindre ${ }^{62}$. Dans les Évangiles des Quenouilles, on recommande plusieurs fois d'utiliser une plante cueillie la nuit de la Saint-Jean, aussi bien pour se faire aimer par son mari que pour assurer l'abondance du lait des vaches. Selon un autre conseil, pour favoriser la lactation, on doit mettre de ces herbes au-dessus de la porte de l'étable des vaches en disant: «Que Dieu les sauve et saincte Bride!», ou encore, frotter tous les jours le récipient à traire (vaissel a moudre) avec des herbes de cette sorte lorsqu'on sonne none ${ }^{63}$.

\section{Ambiguïtés}

Dans l'un de ses sermons contre l'idolâtrie ${ }^{64}$, Bernardin de Sienne (1380-1444) s'attaqua avec véhémence aux pratiques, qui ouvraient, selon lui, la porte au démon. Il en dressa un inventaire assez poussé qui révèle l'une des caractéristiques fondamentales des usages prophylactiques: le syncrétisme entre usages chrétiens et "païens", entre lesquels les utilisateurs ne faisaient aucune différence. La liste la plus détaillée 
concerne la protection contre les maladies. Par exemple, pour éviter les crises d'épilepsie (le "mal caduc») durant l'année à venir, les personnes qui en souffraient habituellement, allaient le jour de l'Assomption ou à la Saint-Barthélemy sautiller et faire d'autres «insanités » dans les églises. Contre le même mal, ils allumaient douze cierges correspondant aux douze apôtres, et rebaptisaient le malade au nom de l'apôtre dont le cierge s'éteignait en dernier. Pour être protégés contre les carreaux d'arbalète, ils en apportaient un à saint Sébastien à sa fête. Pour les carreaux impossibles d'extraire d'une blessure, ils récitaient l'incantation de Longin ${ }^{65}$; contre les blessures, une autre incantation, celle des " Trois bons frères » (ill. 14) ${ }^{66}:$ il s'agissait des formules apotropaïques narratives très répandues. Sans préciser leur contenu, Bernardin mentionna l'usage fréquent d'autres incantations pour toute une variété de maladies; souvent, on portait les formules sur soi sous la forme écrite pour prévenir ou guérir le mal; par exemple, contre les vers dont souffraient les enfants, ou encore contre la fièvre. D'autres coutumes semblaient remonter à des traditions ancestrales qualifiées de païennes, comme le rite de faire passer l'enfant malade entre les racines ou dans le creux d'un chêne ${ }^{67}$.

\section{14. Formule "Trois bons frères » : Pour les plaies guarir. Tres boni fratres ibant...}

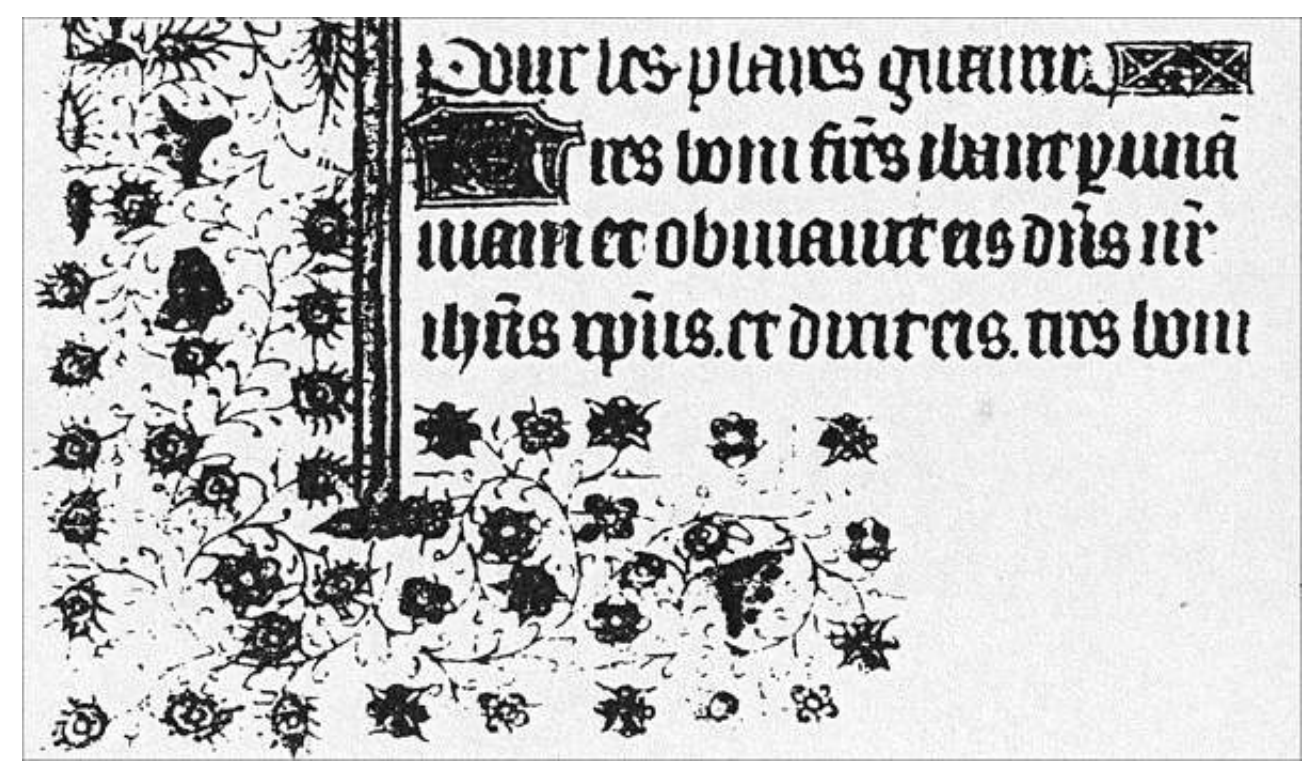

Livre d'Heures, Saint-Brieuc, B. M., ms 1, fol. 169v.

Face aux multiples moyens de la protection individuelle, l'Église manifesta, malgré une apparente sévérité, un comportement plutôt tolérant et souvent ambigu, comme par exemple Antonin de Florence dans son "catalogue de croyances »: "As-tu récité ou fait réciter des incantations pour obtenir la santé ? Celui qui le fait tout en sachant que c'est interdit, commet un péché mortel. Mais celui qui croit, dans sa simplicité, qu'il s'agit là de bonnes oraisons ne commet qu'un péché véniel ${ }^{68} \%$. En général, les auteurs ecclésiastiques essayaient de distinguer entre les pratiques licites et illicites. Heinrich von Gorkum (Gorchen) accepta les rites lorsque les fidèles mettaient leur confiance en Dieu et en un saint, et n'attribuaient pas une valeur intrinsèque et universelle aux objets bénis ${ }^{69}$. Ainsi il considéra qu'il était licite d'écrire une formule liturgique sur les cierges bénis, à la fête de Sainte-Agathe, contre le risque d'incendie ; mais cet usage devenait illicite et supersititieux lorsqu'on pensait que les mots écrits possédaient en 
eux-mêmes la vertu universelle de se protéger contre l'incendie. Même les auteurs du Marteau des sorcières firent preuve d'une certaine tolérance, en définissant les critères des prières et bénédictions illicites : 1 ) les paroles ne doivent contenir rien qui implique une invocation expresse ou tacite du démon ; 2) les formules ne doivent contenir aucun nom inconnu; 3) elles ne doivent contenir aucune fausseté (ex. comme légende apocryphe) ; 4) elles ne doivent être accompagnées d'autres gestes que le signe de la croix ; 5) qu'il n'y ait pas d'importance accordée à la manière d'écrire, de lire, de lier (attacher) la formule ; 6) qu'on n'ait attention qu'à la vénération de Dieu, qu'on attende les effets seulement de la puissance divine ; 7) que l'on s'en remette pour l'effet attendu à la divine volonté ${ }^{70}$.

Tout en essayant d'imposer les limites du superstitieux, les ecclésiastiques, et notamment les inquisiteurs recouraient eux-mêmes aussi à des pratiques rituelles et à des formules qui remplissaient la même fonction que les moyens utilisés par les laïcs pour combattre le mal. Les auteurs du Marteau des sorcières décrivaient plusieurs méthodes contre l'ensorcellement (mauvais... il) : par exemple, une femme dans la ville de Spire, «craignant pour son enfant, elle mit sous lui des herbes bénites, l'aspergea d'eau sainte, lui mit un peu de sel bénit dans la bouche, le signa du signe de la croix ». Pour la protection des lieux, des hommes et des bêtes, «ce sont les mots du titre glorieux de notre Sauveur inscrit aux quatre angles de la maison en forme de croix: Jésus † Nazaréen †Roi † des Juifs" qu'ils préconisent comme les plus sûrs. Les inquisiteurs eux-mêmes devaient se munir de différents sacramentaux : ils portaient sur eux en permanence du sel exorcisé au jour des Rameaux et des herbes bénites, roulés dans la cire bénite et suspendus autour $\mathrm{du} \mathrm{cou}^{71}$; en particulier, le juge devait porter «autour de son cou du sel bénit et diverses autres choses, liés avec les sept paroles du Christ en croix écrite sur une cédule», et, "si cela peut se faire commodément sur son corps nu, un cierge "longueur-du-Christ" $"$ ".

D'un autre côté, les formules apotropaïques pouvaient être détournées à d'autres fins, comme par exemple retrouver un voleur, ou pour la «magie " amoureuse. Vers 1400, Ulrich von Pottenstein rapporta le contenu d'une lettre qu'une "sorcière " de Neunkirchen avait donnée à quelqu'un pour retrouver le voleur de son bien. Les invocations et les procédures dérivaient de la dévotion aux cinq plaies du Christ. La personne lésée devait prononcer entre autres les paroles suivantes: «Les cinq blessures saintes m'aideront pour que toi, voleur, tu sois enchaîné. Pour cela, le saint Christ, né à Bethléem, m'aidera ». Il n'y a pas de doute que les opérations suivantes ont été liées au culte des cinq plaies: « Ensuite, récite cinq Pater. Puis une femme doit filer cinq fils sans les mouiller. Mets-les au-dessus du seuil sur lequel le voleur a marché. Ensuite, dirige tes pas dans la chambre d'où le voleur est sorti avec son butin et fais des cinq fils un fil de cire. Avec celui-ci, mesure du coude jusqu'au bout de l'auriculaire. Fais ensuite de ce fil de cire cinq bougies et allumes-en une chaque jour... ${ }^{73}$ "

En 1428 à Todi, Mateuccia di Francesco, accusée de sorcellerie révéla la formule qu'elle recommanda à une femme battue pour soumettre son mari à sa volonté :

Sta in the (sic)

come stecte Christo / in sé,

sta fixo

come stecte Christo crucifixo,

torna ad me

come torno Christo in sé, 
torna a la voluntà mia, /

come torno Christo a la patria sua ${ }^{74}$.

Or, cette formule servait habituellement à arrêter le sang, et fut considérée très efficace même par des savants comme Jérôme Cardan, qui, ayant coupé par hasard ses lèvres, n'a pu faire cesser le saignement qu'en faisant cette incantation :

Sanguis mane in te

sicut fecit Christus in se.

Sanguis mane in tua uena,

sicut Christus in sua poena.

Sanguis mane fixus, sicut Christus

quando fuit crucifixus ${ }^{75}$.

\section{Permanences}

Les moyens de protection spirituelle utilisés au Moyen Âge traversèrent les siècles et restèrent largement répandus jusqu'au $\mathrm{XX}^{\mathrm{e}}$ siècle, voire jusqu'à nos jours. Ni l'Église ni les progrès de la science n'arrivèrent à faire disparaître les pratiques traditionnelles dont l'enregistrement faisait le bonheur des ethnographes des deux derniers siècles. L'exposition Religions et traditions populaires (1979) ${ }^{76}$ fit la démonstration de la vigueur des croyances apotropaïques et de la diversité des formules et instruments employés à ces fins. Certains de ces objets, comme les tuiles protectrices d'un potier alsacien (1802), avec le monogramme IHS et les trois clous de la crucifixion ${ }^{77}$, témoignent des usages dont il ne reste plus de traces matérielles de l'époque médiévale. Des images de protection, comme celle des Rois mages en Alsace (peinture fixée sous verre), ou celle de sainte Agathe avec l'invocation "Priez pour nous, sainte Agathe. Que Dieu nous préserve d'incendie et d'accident fâcheux » (lithographie, Metz, milieu du XIX ${ }^{\mathrm{e}}$ siècle) ${ }^{78}$, montrent la permanence des traditions apparues à la fin du Moyen Âge. Un petit tableau-reliquaire du début du XIX ${ }^{e}$ siècle, placé dans une maison de Saint-Pierre-desIfs (Eure) près du lit, illustre l'utilisation fonctionnelle des reliques dans la religion domestique : les petites parcelles de reliques furent surmontées d'écriteaux dont un " contre le tonnerre », et un autre « contre le mauvais sort ${ }^{79}$ ".

Dans la médecine populaire, les avatars des réceptaires médiévaux continuaient à circuler $^{80}$, et on pouvait collecter de belles formules de guérison jusqu'à une époque récente dans les régions rurales ${ }^{81}$. Et, encore aujourd'hui, les porte-bonheur perpétuent le souvenir des pratiques ancestrales.

54. Bernard Gui, Manuel de l'Inquisiteur, éd.-trad. G. Mollat, Paris, Belles Lettres, 1964, t. 2, pp. 22-23.

\section{NOTES}

1. Pour une approche plus conceptuelle et théorique de la question, je renvoie le lecteur aux ouvrages suivants: D. Harmening, Superstitio. Überlieferungs- und theoriegeschichtliche Untersuchungen zur kirchich-theologischen Aberglaubensliteratur des Mittelalters, Berlin, E. Schmidt, 
1979 ; J.-C. Schmitt, « Les superstitions », Histoire de la France religieuse, éd. J. Le Goff, R. Remond, Paris, Seuil, 1988, t. 1, pp. 417-551 ; R. Kieckhefer, Magic in the Middle Ages, Cambridge-New YorkPort Chester-Melbourne-Sydney, Cambridge University Press, 1990.

2. Le livre fondamental sur ce sujet reste celui d'A. Franz, Die kirchlichen Benediktionen im Mittelalter, Fribourg, 1909 ; rééd. Graz, 1960.

3. Cf. mon livre intitulé Charmes et prières apotropaïques, à paraître dans la collection «Typologie des sources du Moyen Âge occidental », Brepols, Turnhout, 2002.

4. P. Rézeau, Les prières aux saints en français à la fin du Moyen Âge, Genève, Droz, 1983, t. 2, p. 442.

5. L. Gougaud, "La prière dite de Charlemagne et les pièces apocryphes apparentées ", Revue d'Histoire Ecclésiastique, 20 (1924), pp. 211-238.

6. Médiathèque de Poitiers, ms 42 (257), f. 52.

7. Van Der Leeuw, La religion, dans son essence et ses manifestations, Paris, Payot, 1948, pp. 415-416.

8. Charme du XIVe siècle, Wien, éd. A. Schönbach, "Segen ", Zeitschrift für deutsches Altertum, 24 (1880), p. 308.

9. F. Cardini, «Il 'breve'(sec. XIV-XV). Tipologia e funzione », La Ricerca Folklorica, 5 (1982), pp. 63-75.

10. D. Le Blevec, «Pharmacopée populaire en comtat venaissin : les recettes du notaire Jean Vital (1395) », Razo,4 (1984), pp. 127-131, ici p. 129.

11. Réceptaire occitan-latin, XVe siècle, éd. M. S. Corradini Bozzi, Ricettari medico-farmaceutici medievali nella Francia meridionale, t. I, Florence, Olschki, 1997, p. 237.

12. H. Institoris, J. Sprenger, Le marteau des sorcières, II, I, XVI, p. 370 : « Car à cause de ces mots inconnus et de ces caractères tracés, il y a là-dessous un pacte tacite passé avec le démon /.../ le confesseur doit demander à voir ces charmes et si l'autre ne veut pas les rejeter totalement, il doit détruire les mots inconnus et les caractères et ne permettre dans le reste que les paroles d'Évangile et les signes de la croix ».

13. C. Brunel, Recettes médicales alchimiques et astrologiques du XVe siècle en langue vulgaire des Pyrénées, Toulouse, Privat, 1956, n 362, p. 39.

14. L. Carolus-Barré, «Un nouveau parchemin amulette et la Légende de sainte Marguerite patronne des femmes en couches ", Académie des Inscriptions \& Belles-Lettres, comptes rendus des séances de l'année 1979, pp. 256-275.

15. H. Institoris, J. Sprenger, Le marteau des sorcières, trad. A. Danet, Grenoble, J. Millon, 1997, II, I, XVI, p. 370.

16. Ibid., II, II, VI, p. 414 : « on blâme les 'brefs'que portent les soldats ».

17. A. Lecoy de La Marche, «Interrogatoire d'un enlumineur par Tristan l'Ermite », Revue de l'art chrétien, 35 (1892), p. 396-408; cf. aussi R. Favreau, « Piété et superstition en Poitou », Bulletin de la Société des Antiquaires de l'Ouest, (1985), pp. 155-158.

18. P. Studer, J. Evans, Anglo-Norman Lapidaries, Paris, Champion, 1924, p. 37, v. 249 sq.

19. Ibid., pp. 45-46, v. 431 sq.

20. E. Babelon, Histoire de la gravure sur gemmes, Paris, 1902, pp. 86-97.

21. Ibid., p. 290.

22. J. Labarte, Inventaire du mobilier de Charles $V, \mathrm{n}^{\circ} 618$.

23. Cf. D. Alexandre-Bidon, « La dent et le corail ou La parure prophylactique de l'enfance à la fin du Moyen Âge", Razo, 7 (1987), p. 5-35. Cf. aussi J. Yarza Luaces, «Fascinum. Reflets de la croyance au mauvais œil dans l'art médiéval hispanique », Razo, 8 (1988), pp 113-127.

24. J. Evans, Magical Jewels of the Middle Ages and the Renaissance particularly in England, Oxford, 1922 , p. 126, ill.

25. Age of Chivalry. Art in Plantagenet England 1200-1400 (catalogue), éd. J. Alexander \& P. Binski, Londres, Royal Academy of Arts, 1987, n 647, pp. 484-485.

26. Jean de Mandeville, Voyage autour de la terre, ch. XIII, trad. et commenté par Ch. Deluz, Paris, Les Belles Lettres, 1993, p. 85. 
27. O. M. Dalton, Franks Bequest. Catalogue of te Finger Rings. Early Christian, Byzantine, Teutonic, Mediaeval and Later, Londres, 1912, surtout pp. 109-111, et pp. 135-142.

28. A. Ward, J. Cherry, Ch. Gere et B. Cartlidge, La bague de l'Antiquité à nos jours, Fribourg, Office du Livre, Paris, La Bibliothèque des Arts, 1981 ; cf. surtout J. Cherry sur « Les bagues médiévales ", pp. 51-86.

29. M. Bloch, Les rois thaumaturges. Etude sur le caractère surnaturel attribué à la puissance royale particulièrement en France et en Angleterre, Paris, Gallimard, 1983 (1re éd.1924), p. 159 sq., 445 sq.

30. D. Bruna, Enseignes de pèlerinage et enseignes profanes (Catalogue), Musée National du Moyen Âge, Thermes de Cluny, Paris, Réunion des musées nationaux, 1996.

31. D. Bruna, "Témoins de dévotion dans les livres d'Heures à la fin du Moyen Âge ", Revue Mabillon, N. S. 70 (1998), pp. 127-161.

32. J. Cherry, The Middleham Jewel and Ring, York, The Yorkshire Museum, 1994.

33. D. Kötzsche, Der Quedinburger Schatz wieder vereint, Quedlinburg, Kunstgewerbemuseum, 1992, pp. 106-108, $\mathrm{n}^{\circ} 43-46$.

34. X. Barbier de Montault, Traité liturgique et canonique et symbolique des Agnus Dei, Rome-Paris, 1865 ; cf. aussi E. Mangenot, « Agnus Dei », Dictionnaire, col. 605-613.

35. D. Kötsche, Der Quedlinburger Schatz, pp. 100-102, n 34-35.

36. Les fastes du gothique. Le siècle de Charles V, Paris, Éditions de la Réunion des musées nationaux, 1981 , pp. $235-236,{ }^{\circ} 190$.

37. Ibid., p. $266, \mathrm{n}^{\circ} 215$.

38. E. Taburet-Delahaye, L'orfêvrerie gothique (XIII -début XV siècle) au Musée de Cluny (Catalogue), Paris, Éditions de la Réunion des musées nationaux, 1989, pp. 131-134, nº 48.

39. Ibid., pp. 248-250, $\mathrm{n}^{\circ} 131$.

40. Inventaires mobiliers et extraits des comptes des ducs de Bourgogne de la maison de Valois (1363-1477), éd. B. Prost, t. I : Philippe le Hardi, Paris, 1902, p. 102, n 648.

41. A. Vauchez, La sainteté en Occident aux derniers siècles du Moyen Âge, Rome, Ecole Française de Rome, 1988, p. 529.

42. Dieu en son royaume. La Bible dans la France d'autrefois, XIII ${ }^{e}-X V I I I^{e}$ siècles, Paris, Bibliothèque Nationale, Cerf, 1991, p. 68, ill. 51.

43. E. de Kayser, "Souhaits et images de Nouvel An dans quelques pays d'Europe. Incunables xylographiques du $\mathrm{XV}^{\mathrm{e}}$ siècle", Bulletin de l'Association historique, artistique et archéologique "Le Vieux Papier", janv. 1975, fasc. 255, pp. 271-277, ici p. 275.

44. L'Inventaire du trésor du dauphin futur Charles V. 1363. Les débuts d'un grand collectionneur, éd. D. Gaborit-Chopin, Nogent-le-Roi, Librairie des Arts te Métiers, Éditions J. Laget, 1996, p. 67, nº 67.

45. J. Evans, Magical Jewels, p. 138.

46. Jacques de Voragine, La légende dorée, trad. J.-B. M. Roze, Paris, Garnier-Flammarion, 1967, t. 1, p. 52 ; évoqué par J.-C. Schmitt, « Les superstitions » (cf. n. 1), pp. 514-515.

47. H. Institoris, J. Sprenger, Le marteau des sorcières, II, XVI, p. 369.

48. Rigord, Gesta Philippi Augusti, § 52, éd. H. F. Delaborde, œuvres de Rigord et de Guillaume le Breton, historiens de Philippe-Auguste, t. 1, Paris, 1882, pp. 79-80.

49. Cf. mon article «La blessure qui guérit. Les effets apotropaïques des plaies du Christ au Moyen Âge (XIII ${ }^{\mathrm{e}}-\mathrm{XV}^{\mathrm{e}}$ siècle) ", à paraître dans les Cahiers du GERHICO, $\mathrm{n}^{\circ}$ spécial sur la Blessure, Poitiers, 2001.

50. X. Barbier de Montault, «Les mesures de dévotion", Revue de l'art chrétien, 25 (1881), pp. 360-419 ; L. Gougaud, «La prière dite de Charlemagne et les pièces apocryphes apparentées ", Revue d'Histoire Ecclésiastique, 20 (1924), pp. 211-238.

51. A. Lecoy de la Marche, «Interrogatoire... », pp. 406-407.

52. Pierre le Vénérable, Les merveilles de Dieu (De miraculis), trad. J.-P. Torrell et D. Bouthillier, Fribourg et Paris, 1992, pp. 70-72. 
53. Étienne de Bourbon, Anecdotes historiques, légendes et apologues, §317, éd. A. Lecoy de La Marche, Paris, 1877, pp. 266-267.

55. T. Hunt, Popular Medicine in Thirteenth-Century England, Cambridge, Brewer, 1990, pp. 85-86.

56. J. Klapper, «Das Aberglaubensverzeichnis des Antonin von Florenz", Mitteilungen der schlesischen Gesellschaft für Volskunde, 21 (1919), p. 63-101; trad. dans C. Lecouteux, Mondes parallèles. L'Univers des croyances du Moyen Âge, Paris, Champion, 1994, pp. 113-118, ici p. 114.

57. Trad. dans C. Lecouteux, Mondes parallèles, pp. 116-117.

58. Les Évangiles des Quenouilles, éd. M. Jeay, p. 93. Cf. aussi R. Vaultier, Le folklore pendant la guerre de Cent Ans d'après Les Lettres de Rémission du Trésor des Chartes, Paris, 1965, pp. 45-49.

59. H. Institoris, J. Sprenger, Le marteau des sorcières, II, II, VII, p. 428.

60. Ibid., p. 430.

61. Ibid., p. 428.

62. Rutebeuf, «Le dit de l'herberie ", dans œuvres, éd. Jubial, 1874, t. 2, p. 60. Cf. aussi R. Vaultier, Le folklore, pp. 75-76.

63. Les Évangiles des Quenouilles, éd. M. Jeay, Paris, Vrin et Montréal, Les Presses de l'Université de Montréal, 1985, p. 108, 136.

64. S. Bernardinus Senensis, Opera omnia, t.I, Florence, 1950, Sermo X: De idolatriae cultu, pp. 105-118, en particulier pp. 113-116.

65. Charme narratif qui fut très répandu : on évoqua l'acte de Longin qui avait transpercé le côté du Christ; la blessure ne lui faisait pas mal ; on souhaite que la blessure du malade actuel soit guérie aussi sans douleur, sans gangrène.

66. Charme narratif également très souvent attesté, parfois combiné avec celui de Longin. Trois bons frères rencontrent le Christ qui les questionne de leur but de voyage ; ils répondent qu'ils cherchent une herbe pour soigner les plaies sur le mont des Oliviers. Le Christ leur propose l'huile d'olive er de la laine de mouton et un charme (celui de Longin en général). Ce charme fut parfois inclu dans les Livres d'Heures : cf. le ms I de la Bibliothèque Municipale de Saint-Brieuc $\left(\mathrm{XV}^{\mathrm{e}}\right.$ siècle).

67. Ce rite est mentionné dans l'exemplum de saint Guinefort raconté par Étienne de Bourbon au XIII siècle : les femmes apportaient leur enfant malade dans un bois où le chien " martyr » fut inhumé ; «quand elles y parvenaient, elles offraient du sel et d'autres choses; elles pendaient aux buissons alentour les langes de l'enfant; elles plantaient un clou dans les arbres qui avaient poussé en ce lieu ; elles passaient l'enfant nu entre les troncs de deux arbres : la mère, qui était d'un côté, tenait l'enfant et le jetait neuf fois à la vieille femme qui était de l'autre côté » (texte et trad. dans J.-C. Schmitt, Le saint lévrier. Guinefort, guérisseur d'enfants depuis le XIII ${ }^{e}$ siècle, Paris, Flammarion, 1979, pp. 13-17).

68. Trad. dans C. Lecouteux, Mondes parallèles, p. 117.

69. Heinrich von Gorkum, Tractatus de supertitiosis quibusdam casibus (ca. 1425), J. Hansen, Quellen und Untersuchungen zur Geschichte des Hexenwahns, Bonn, 1901, pp. 87-88.

70. H. Institoris, J. Sprenger, Le marteau des sorcières, pp. 413-414.

71. Ibid., p. 494.

72. Ibid., p. 498.

73. D. Harmening, « Magiciennes et sorcières. La mutation du concept de magie à la fin du Moyen Âge ", Heresis, 13-14 (1990), pp. 423-443, ici pp. 429-430.

74. D. Mammoli, «The Record of the Trial and Condemnation of a Witch, Matteuccia di Francesco, at Todi, 20 March $1428 »$, Res Tudertinae, 14 (1972), pp. 15-16.

75. J. Cardanus, De subtilitate, livre XVIII : De mirabilibus, Paris, 1550 ; cité par Ch. Lea, Materials, t. II, pp. 436-437.

76. Religions et traditions populaires. Musée national des arts et traditions populaires, 4 décembre 1979-3 mars 1980 (catalogue), Ministère de la Culture et de la Communication, Éditions de la Réunion des Musées nationaux, 1979. 
77. Ibid., n 295-297, pp. 96-97.

78. Ibid., $\mathrm{n}^{\circ} 301$ et 302 , p. 99.

79. Ibid., $\mathrm{n}^{\circ} 305$, p. 100.

80. Cf. notamment M. Bouteiller, Médecine populaire d'hier et d'aujourd'hui, Paris, Maisonneuve et Larose, 1966.

81. P. Bertrand-Rousseau, Ile de Corse et magie blanche. Etude des conduites magico-thérapeutiques en Corse, Paris, Publications de la Sorbonne, 1978.

\section{AUTEUR}

\section{EDINA BOZOKY}

Université de Poitiers 